\title{
A SYMPOSIUM ON THE SUBCONSCIOUS
}

\section{IV}

\author{
BY PIERRE JANET ${ }^{1}$ \\ Professor of Psychology, College de France
}

My dear Dr. Prince:

TOU have set me quite a difficult task and one which I hardly feel capable of accomplishing to your entire satisfaction. You ask me to take a stand with regard to the metaphysical theories which are developing today and which seem to have for their point of departure the study of phenomena formerly described by me under the name of the "Subconscious." These studies, already old, since I published them between the years 1886 and 1889 , do not permit me to take part in this serious quarrel; they have a much more restricted and much less ambitious range. While the researches of the present day, whether they have a spiritualistic or a materialistic tendency, attain to the summit of the highest metaphysics, my old studies, very modest as they were, simply endeavored to throw light upon, describe and classify certain phenomena of pathological psychology.

Disturbances of the notion of personality are freely met with in psychiatric studies. One finds not only disturbances in the conception which patients make of their own person, when they pretend to be a king or an animal, but also one very often meets with curious alterations in the assimilation, the incorporation of such and such a phenomenon with that feeling they have of their own person. Indeed, it is undeniable that there takes place in us a certain classing of psychologic phenomena; some are attached to the group of the phenomena of the outside world, others are grouped about the idea of our person. This idea, whether exact or not, which is probably in a great measure a product of our social education, becomes a center about which we range certain

\footnotetext{
sTranslation by Dr. J. W. Courtney, membre correspondant etranger de la Societe de Neurologie de Paris.
} 
facts, while others are placed outside of ourselves. Without discussing the value and the nature of this distribution as it is brought about in the practically normal mind, I state simply the fact that certain patients attach badly to their personality certain phenomena, while others do not hesitate to consider the same facts as entirely personal.

In the delirium of typhoid fever one of my patients used to say to me: "Just think of my poor husband who has such a frightful headache; see how my children suffer in their stomachs, somebody is opening their abdomen." She attributed to other people the sensations of suffering which ordinarily we do not hesitate to attribute to ourselves. One meets much more often still with a somewhat different illusion in that large class of patients which I have described under the name of "psychasthenics;" many of them repeat incessantly such remarks as, "It is not I who feel, it is not I who eat, it is not I who speak, it is not I who suffer, it is not I who sleep; I am dead and it is not I who see clearly," etc. $^{\mathrm{I}}$

It is easy to determine that in these patients their movements are correct, their diverse sensations are correctly conserved, even their kinaesthetic and visceral sensations; but the subject nevertheless declares that he does not attach them to his personality; as far as he may he acts as if he did not have them at the disposition of his person. A patient of this sort, recently described by Séglas, declared that he had no memory and acted as far as possible as if he had really lost all memory, although it was easy to prove that he had in reality forgotten nothing. ${ }^{2}$ The apparent trouble of memory just as the apparent antecedent trouble of sensation and movement was nothing more than a disturbance in the development of the idea and the feeling of the personality.

Among these psychasthenics the disturbance of the personality is not total. It is clearly manifest in certain mental operations which may aptly be called superior, - that is to say, in the judgment of recognition by which the attention

II, p. 40, 35t.

2 Journal de psychologie normale et pathologique, March, 1907, p. 97 . 
attaches the new mental content to the old, in language with reflection and in voluntary action. But elementary operations of the personality seem to be preserved; consciousness, that act by which a multiplicity and diversity of states is attached to a unity, seems to survive. The subject declares that it is not he who remembers this or that act, that it is not he who sees this or that tree, but he remembers it nevertheless and continues to see it. At least it is manifest to us that his mind continues to see the tree, since he describes the changes which take place in it and tells us: "The tree is green, its leaves flutter, but it is not I who see it." The disturbance of the personal perception appears not to be profound.

This incomplete character of the disturbances of the personality is found in all the accidents of these psychasthenic patients; they have obsessions but are not completely insane and always recognize the absurdity of their obsessing ideas; they have impulses but do not carry them out; they have phobias concerning acts but never real inability to perform acts, or real paralyses; they have interminable doubts but no true amnesias. It is the striking trait of their character that they never have any symptom in its completeness, and this incomplete character of the disturbances of their personality falls within a general law.

Now there is another psychosis, all the symptoms of which might easily be put in a parallel column with those of psychasthenics, and that is hysteria. This mental disease has for its essential characteristic exaggeration, the carrying to an extreme of all preceding symptoms. Instead of the preceding obsessions with doubt, there are in the monoideistic somnambulism of hysterics fixed ideas which develop to the most extreme degree, with complete hallucinations and impulses; in place of doubt there is true amnesia; in place of phobias we meet with complete paralyses. It is, therefore, interesting to see the form which the trouble of the personality, just described as incomplete in the previously mentioned disease, will take in hysteria.

Doubtless certain hysterics at times express, with regard to certain sensations, judgments analogous to those of psychasthenics. 
A patient formerly cited by Professor James used to say: "My arm is no longer a part of me, it is foreign to me, it is an old stump." This, however, is rather exceptional and most commonly one meets with a different order of facts. In the wake of certain crises in which fixed ideas have developed superabundantly and completely in the form of feelings, acts and hallucinations, which we have called mono-ideistic somnambulisms, the patient acts as if he were completely ignorant of what has taken place; he does not doubt his memories, he does not declare them foreign to his person; he does not speak of them at all, he ignores them. The same subject has both legs paralyzed for certain periods of time, and yet he does not merely say that it is not he who walks, he does not walk at all. If one pricks or pinches his motionless legs, he does not merely say that the sensation is foreign to him, that it no longer belongs to him, that it is not he who feels; he says nothing at all, for he does not seem to feel it in any way. The loss which the personality suffers, the alienation of the phemonena seems to be more complete than in the preceding case. Shall we say, however, that the cases are in nowise comparable?

The psychasthenic still retained his memories, his voluntary acts, his sensations. It is true that he said, "It is not I who remember, I who move and feel," but he proved that he did feel by describing correctly objects placed before him.

In the hysteric these psychologic phenomena are merely suppressed, it is quite another disease, and that is exactly what I formerly tried to show, although in opposition to the opinion current at that time. With a little more precaution than is necessary with the psychasthenic but in the same way, by more carefully avoiding attracting attention of the patient to the expression of these phenomena, one may demonstrate perfectly their existence in as complete a form as in the so-called normal individual. Take the case of a young girl of twenty years who in her somnambulistic periods indulges in fugues of several days' duration, far from the paternal roof. After her fugues she appears to have lost completely all memory of them, although she seems incapable of telling you why she went away or where she 
went. Under distraction and while she was thinking of something else, I put a pencil in her right hand and she wrote me the following letter apparently without cognizance of what she was doing.- "I left home because mamma accuses me of having a lover and it is not true. I cannot live with her any longer. I sold my jewels to pay my railroad fare. I took such and such a train," etc. In this letter she relates her entire fugue with precision although she continues to contend that she remembers nothing about it. Another case, that of a man who seemed to have both legs paralyzed, rapidly traverses roofs during a somnambulism and even during the waking state makes with his limbs any movements one desires, if such movements are called for under favorable conditions. These people who seem not to see clearly or not to feel anything in their hands, describe to you in a subsequent somnambulism or by means of the writing of which I have just spoken, or by still other methods, all the details of objects placed before their eyes or brought in contact with their hands. Are we not obliged to conclude as in the preceding case, that sensations are really conserved, although the subject tells us that he does not feel them? These are interesting though perfectly commonplace clinical phenomena, since it is easy to see that all hysterical accidents are fashioned on the same model. They are analogous to the depersonalizations of psychasthenics, but they are not identical with them. I tried to sum them up under the word "subconscious," which, from my point of view, simply designates this new form of the disease of the personality.

Since the time when I first began to employ the word "subconscious," in this purely clinical and somewhat prosaic sense, I must admit that other authors have employed the same word in a sense infinitely more ambitious. The word has been used to designate marvelous activities which exist, so it appears, within ourselves without our even suspecting their existence, and which become the source of our virtues, of our enthusiaşms and of the divination of genius. This recalls that amusing saying of Hartmann: "Let us not despair at having a mind so practical and so lowly, so unpoetical and so little spiritual; there is within the innermost sanctuary of each of us, a marvelous something of which 
we are unconscious, which dreams and prays while we labor to earn our daily bread." I intentionally avoid discussing theories so consoling and perhaps true withal; I simply remind myself that I have something quite different to do. The poor patients whom I studied had no genius; the phenomena which had become subconscious with them were very simple phenomena, such as among other men are a part of their pesonal consciousness and excite no wonder. They had lost the power to will and the knowledge of self; they had a disease of the personality, nothing more.

In connection with these same facts and in making use of the same word, their theories have touched the great problem of the connections between soul and body, between thought and brain. Are cerebral phenomena always accompanied by psychologic phenomena? When psychologic phenomena diminish, when they are reduced to their simplest expression do they not tend to disappear, and may not one then say that nervous phenomena subsist alone? May not certain coördinate movements which are but ill perceived by patients during their convulsions, and in choreas, be attributed to simple cerebral phenomena without interjecting the notion of psychologic phenomena? If we were really determined to baptize these physiologic phenomena without thought of the name subconscious, might we not on account of the analogy of the name say that all the phenomena of somnambulism or of automatic writing is easily explainable "by phosphorescent shadows which flit across certain centers of the cerebral cortex"!

Far be it from me to discuss these fine theories which seduce certain minds by their scientific appearance, and which after all do probably contain some truth. I am content to remark, that that is quite another problem. Doubtless the question of the connections between thought and brain may be discussed with regard to somnambulism as well as with regard to nearly every fact of normal life, but in my opinion there is no good reason why this great problem should be particularly raised in this connection. The assimilation of the conduct of the somnambulist, of the execution of the suggestion, of a page of automatic writing, with inco" rdinate convulsive movements is pure childish- 
ness. These diverse acts are identical with those which we are accustomed to observe in persons like ourselves and to explain by the intervention of the intelligence. Undoubtedly one may say that a somnambulist is only a mechanical doll, but then we must say the same of every creature. These are useless reveries. In our ignorance, we simply know that certain complex facts, like an intelligent reply to a question, depend upon two things which we believe associated; superior cerebral mechanism and a phenomenon which we call an effect of consciousness. We find the same characteristics in the so-called subconscious phenomena, and we must suppose back of them the same two conditions. To be able to affirm anything else we should need to possess precise knowledge concerning the expression of superior or inferior phenomena of cerebral activity, concerning the loss of the association of consciousness with cerebral phenomena, knowledge which we positively do not possess. Certainly it ought not to be with regard to half understood symptoms of a mental disease that we should try to resolve these great problems of metaphysics. In my opinion, we have got other psychologic and clinical problems to resolve concerning the subconscious without embarrassing ourselves with these speculations. You see that I am today more occupied than formerly with the relations which exist between the depersonalization of psychasthenics and the subconsciousness of hysterics. We must study the intermediate types which are met with much oftener than I had thought. It is necessary to determine if certain characteristics of the one disease are not found in the other. Does not the hysteric herself possess a sort of insane belief which makes her relinquish certain phenomena? Up to what point is she sincere in her declarations of ignorance? Does she not to a certain extent deceive herself? By what steps does she arrive at the complete separation of phenomena which seem to exist in certain cases? Do the psychologic phenomena thus dissociated always retain their properties, are they not more or less transformed? The same problem presents itself in connection with the muscular phenomena, for in the hysterical contracture it does not seem to me exact to say that the muscular contraction remains absolutely what it was in 
normal movements. There are many other clinical problems of great importance which it seems to me must be studied. None of these researches can be made without exact and long continued observations carried on under good conditions, and the very least of them is to my mind more important than all the huge tomes full of speculations put together. It seems to me not difficult to gather from these few reflections the reply to your questions, or, at least, to certain of them. ${ }^{\text {x }}$

[I. What do you understand by the "Subconscious?"]

The word "subconscious" is the name given to the particular form which disease of the personality takes in hysteria.

[2. Does "doubling" (Janet) of consciousness ever occur whether normally or pathologically? If not, how would you explain the various so-called subconscious phenomena of abnormal psychology (automatic writing, speech, etc.]?

This word is not a philosophical explanation; it is a simple clinical observation of a common character which these phenomena present.

[3. Does the subconscious always represent or depend upon the doubling of consciousness? If so, must there be a lack of awareness on the part of the personal consciousness for the second dissociated group of ideas ?]

There exist all sorts of intermediate pathologic forms between the doubt of the psychasthenic and the subconsciousness of the hysteric.

[4. Is there normally in every individual a second group of co-acting ideas of which the individual is not aware (a so-called secondary consciousness)? If so, are such ideas discreet or systematized ?]

It is possible, for all pathologic phenomena have their germ in normal physiology.

[5. If doubling occurs, is it always pathological? If so, how do you explain automatic writing, post-hypnotic phenomena, like unconscious solutions of arithmetical problems and similar phenomena in normal people ?]

I A serles of tea questions were sent to each contributor to this symposium, suggesting points on which it was thought desirable to obtain expressions of views and to keep the discussion within certain limits. Professor Janet concludes with answers to eight of these questions. I have interpolated ieach question in brackets in his article before the answer in order that the latter may be anderstood-EDtrok. 
Clear-cut phenomena truly comparable to the subconsciousness of hysterics are infinitely rare in the normal mind. When they are really noted by competent observers they must be regarded as unhealthy accidents of a more or less transient character, and in general, as I have always observed, of a somewhat sinister omen.

Furthermore, these discussions of the words health and disease are absolutely puerile and recall the sophism of the Greeks about the bald-headed man. A phenomenon is morbid when it is most often associated with other symptoms of a well recognized disease and when it disappears with the disease. Such indeed is the characteristic feature of somnambulism and of automatic writing, which can no longer be evoked in hysterics when they recover from their disease.

[6. Do you include under the term subconscious all conscious experiences that have been forgotten, and which are capable of being synthesized with the personal consciousness at any given moment regardless of whether the forgotten experiences are co-acting or not (Sidis)? (In this case subconsciousness becomes co-extensive with the forgotten and out of mind.)]

It seems to me difficult to reply to this question when we know so little concerning the form in which our memories are preserved when they are not called forth.

* [7. Do you limit the term solely to the conscious states which are in co-activity at any given moment, but of which the subject is not aware?]

The word "subconsciou's" seems to me rather to apply to this more clearly cut case.

[8. Do you base the conception of the subconscious on the fact of awareness on the part of the individual for certain conscious states, so that there would be different degrees of subconsciousness corresponding to different degrees of awareness? For example, as in absent-mindedness and as represented by the theory of the "fringe of the focus of consciousness."]

There are evidensly relations between all these phenomena, but we must avoid confounding them with one another; analysis compels us to establish some discontinuty between the facts.

So here, my dear Dr. Prince, you have the answers 
requested. I fear that they will hardly satisfy your readers. An investigation of this sort does not resolve the problems once and for all; it merely brings the different opinions into competition as they were before. I hope that it may interest at least some few and lead them to psychological observations which will be of lasting utility to science.

With my most sincere regards,

Dr. Pierre Janet

\section{V}

BY MORTON PRINCE

Professor of Neurology, Tufts College Medical School

$\mathrm{I}^{\mathrm{N}}$

the prefatory note to. this symposium in the last number of THE JOURnal (p. 22) six different meanings in which the term "subconscious" is nowadays used were defined. All but the first and fourth of these meanings involve different interpretations of the same observed facts. In a symposium of this kind three of these only need to be considered; namely, those which Professor Munsterberg has so clearly distinguished and explained, as the points of view of the layman, the physician and the theoretical psychologist. As the first of these three hangs upon the validity of the second, we need only take up for discussion the two last. These two offer interpretations of facts which are not in dispute. Let me state over again the problem:

According to the first of these two interpretations (Professor Muinsterberg's and my second type), so-called automatic writing and speech, post-hypnotic phenomena like the solution of arithmetical problems and various abnormal phenomena, of the origin of all which the subject is ignorant, are the manifestations of dissociated ideas of which the subject is unawa-e and which are therefore called subconscious. Thus a "doubling" of consciousness results consisting of the personal self and the subconscious ideas. I prefer myself the term co-conscious to subconscious, partly to express the notion of co-activity of a second co-conscious- 
ness, partly to avoid the ambiguity of the conventional term due to its many meanings, and partly because such ideas are not necessarily sub-conscious at all; that is, there may be no lack of awareness of them. The co-conscious ideas may be very elementary and consist only of sensations and perceptions which have been split off from the personal consciousness, as in hysterical anesthesiae, or they may consist of recurring memories of past experiences. Under certain conditions by a process of synthesizing these ideas and assimilation of them with a greater or less amount of the personal self, which is thereby attenuated, in its faculties, quite large dissociated systems of subconscious ideas may be formed and give rise to the complicated phenomena for which an interpretation is desired.

According to the opposing hypothesis, all these phenomena are explainable as the manifestations of pure physiological processes unaccompanied by ideas. The apparently intellectual and purposive acts as well as volition and memory are performed by brain processes alone to which no consciousness belongs. Such acts differ only in complexity from such other physiological processes which carry on the digestion and other functions of the body, on the one hand, and the spasmodic jerkings and twitchings, seen in chorea, epilepsy and other abnormal affections, on the other. "Unconscious cerebration," Carpenter called it years ago. Which of these two interpretations is correct? Professor Münsterberg is absolutely right in saying " no fact of abnormal experience can by itself prove that a psychological and not a physiological explanation is needed; it is a philosophical problem which must be settled by principle before the explanation of the special facts begins." The principle is the existence of dissociated subconscious ideas. Are there such things?

With the meaning of this problem well before the mind it becomes manifest that before the fundamencal principle of dissociated ideas is definitely established, it is the sheerest waste of time to discuss larger problems, such as the extent of the subconscious symptoms, whether they belong to the normal as well as the abnormal mind, whether they form a "self," a secondary self (third meaning), etc. These and others are important but secondary problems. 
Above all is it a wasteful expenditure of intellectual energy to indulge in metaphysical speculations regarding the existence and functions of a mystical subliminal self (Myers), transcending as it does all experience and everything that even a "subconscious self" can experience. The point then which we have to determine at the very beginning of the inquiry is this: Do ideas ever occur outside the synthesis of the personal self-consciousness under any conditions, whether of normal or abnormal life, so that the subject becomes unaware of these? Or, putting the question in the form in which it is prescribed to the experimenter: Do phenomena which appear to be the manifestations of a subconscious intelligence necessitate the postulation of dissociated ideas, or are these phenomena compatible with the interpretation that they are due to pure physiological processes without psychical correlates?

The only grounds which I have for believing that my fellow beings have thoughts like myself are that their actions are like my own, exhibit intelligence like my own, and when I ask them they tell me they have consciousness, which as described is like my own. Now, when I observe the so-called automatic actions, I find that they are of a similar character, and when $I$ ask of whatever it is that performs these actions, Whether it is conscious or not? the written or spoken reply is, that it is and that consciously it feels, thinks and wills the actions, etc. The evidence being the same in the one case as in the other, the presumption is that the automatic intelligence is as conscious as the personal intelligence. The alternative interpretation is, not that a physiological process is lying, because lying connotes ideas, but that in some way it is able to rearrange itself and react to another person's ideas expressed through spoken language exactly in the same way that a conscious intelligence lies!

The phenomena which occur in the neatést and most 
precise form and which, from the fact that they can be induced, modified and examined at will, are best adapted for experimental study, are so called automatic writing and speech. We will therefore take these for examination and see if they ever require the interpretation of a secondary intelligence of a psychical nature.

When automatic writing is produced in its most highly developed form, the subject with absolutely unclouded mind, with all his senses about him is able to orient, think and reason as if nothing unusual is occurring. He may watch with unconcerned curiosity the vagaries of the writing pencil. In other words, he is in possession of his normal waking intelligence. Meanwhile his hand automatically produces perhaps long discourses of diverse content. But he is entirely unaware of whát his hand is writing and his first knowledge of its content comes after reading the manuscript. We then have intelligence No. I and writing manifestations which may or may not be interpreted as having been produced by a conscious intelligence No. 2. But writing of this sort is not always produced with intelligence No. I as alert as this.

On the contrary, often and perhaps most frequently the writer falls into a drowsy condition in which he imperfectly orients his surroundings, and if he is reading aloud according to the common method of conducting the experiment, he is only dimly conscious of what he is reading. This extinguishing of consciousness in intelligence No. I may go further and he may not hear when spoken to or feel when touched. He reads on mechanically and without consciousness of the matter he is reading. In other words, he has become deaf and tactually anesthetic and blind to everything but the printed characters on the page before him, and for even these mind-blind. In this state then there is practically extinguishment of all sense perceptions and intellectual thought, and finally the impairment of consciousness may be carried so far that he actually goes to sleep. Ask intelligence No. 2 what has become of No. I, and the answer may be, "He has gone to sleep."'

In other words, intelligence No. I has disappeared, but intelligence No. 2 continues.

This answer was given by a subject observed while this paper was being prepared. 
Now to interpret the automatic writing produced when this great impairment of intelligence No. I has taken plate as subconscious phenomena and due to subconscious intelligence whether physiological or psychological is to overlook the facts as presented. These are not phenomena of a subconscious intelligence but of an alternating intelligence or personality. The complete suppression of intelligence No. I has left but one intelligence, that which had been under other conditions intelligence No. 2. Unless the physiological interpretation be maintained the writing has ceased to be automatic in the sense in which the term was originally used and has become what, for the time being, is the primary intelligence although a different one from that which was originally awake. I say different because if we examine the content of the writing we may find it is made up of memories of past experiences which were entirely forgotten by the original intelligence No. I and gives evidence of a personality differing in character, volitions, sentiment, moods and points of view, of a character differing in a large degree from that of the waking intelligence. The writing may be an original composition involving thought and reason comparable to that exhibited by a normal mind. Such compositions are of great interest from the light they throw upon the origin and development of secondary personalities, but with that we have nothing to do here. At present the only interest we have in such compositions is the evidence which they offer for the interpretation of such a personality. That is to say, whether its intelligence is the exhibition of physiological or psychological processes. To arrive at a satisfactory interpretation, we must study the behavior of the personality to its environment. If we speak to it, it answers intelligently in writing, though intelligence No. I fails to respond. If we prick the hand, we obtain a similar response and lack of response from intellgence No. 2 and No. I respectively, and the same with the other senses. It exhibits spontaneity of thought and its faculties are curtailed in the motor sphere alone in which it retains power only to move the muscles of the arm and hand; but even

$1 \mathrm{By}$ this is not meant that it has the same degree of knowledge and capacity for intellectual thought possessed by the original personality, No. $x$, but on that it has all the different kirds of intelligence possessed by a normal person. 
here in the motor sphere its faculties are not necessarily so limited for it may break out into speech and may exhibit various sporadic movements. It has lost only a general coördinating control over the whole body. In the motor sphere, therefore, its loss is not so great as that which has befallen intelligence No. I. In fact, we have here a condition very similar to that of some persons in deep hypnosis. The main point is that now we have to do with an alternating intelligence, not a co-intelligence. Is it an alternating consciousness?

The next thing to note is that in passing from automatic writing, which is performed while intelligence No. I is completely alert, to writing which is performed while this intelligence is completely or nearly extinguished, we pass through insensible gradations from one condition to the other and we must infer that the intelligence must be the same in kind, physiological or psychological, which produced the writing in the one case as in the other. If the alternating intelligence in the latter case is psychological, the subconscious intelligence in the former must be the same, for there is no place where we can stop and conclude - here the physiological ends and the psychological begins.

In the alternating intelligence producing automatic writing we have an alternating personality. We have here substantially the same condition that is observed, first, in some hypnotic states; second, trance states; third, "fugues," spontaneous somnambulism and post-epileptic states; fourth a state not very different from normal sleep with dreams, forgotten on waking; and fifth, certain states of deep abstraction. In none of these has there ever been raised the doubt as to the conscious character of the intelligence. All are "alternating" states and some are alternating personalities. In the first group, suggestions requiring conscious intelligence are comprehended, remembered and acted upon; in the second, writing and speech are manifested which can only be interpreted as the product of thought; in the third and fourth, the thoughts and dreams can afterwards be regained by certain technical devices; and in the last the conscious processes are remembered. 
Let us go further with our experiment and take a case exhibiting automatic writing where intelligence No. I remains unimpaired. We hypnotize such a subject. When asked what sort of intelligence it was that did the writing, he replies that he remembers perfectly the thoughts, sensations and the feelings which made up the consciousness of which intelligence No. I was not aware and that this consciousness did the writing. Still, it may he maintained that this in itself is not proof but that the hypothesis is permissible, that these memories are sort of hallucinations, and that in hypnosis what were previously physiological processes now have become reawakened and have given rise in the hypnotic synthesis to psychical memories. We shall then have to go further and seek for additional evidence.

Al.tomatic writers may be divided into two classes; namely, those who at the moment of writing are entirely unaware of what the hand is writing; and those in whom at the moment of writing ideas corresponding to written words surge apparently from nowhere without logical associative relation into the mind. Mrs. H., for example, is an excellent automatic writer of the second class. At the moment when the pencil writes ideas which it is about to express arise at once in her consciousness so that she is herself in doubt as to whether she writes the sentence volitionally, or whether it is written automatically entirely independently of her will. Sometimes while writing, the ideas come so rapidly that unable to express them with sufficient celerity with the pencil she bursts out into voluble speech. To test her doubt, she is given a pencil and told not to write. Then she finds herself without control of her hand, and, in fact, the pencil writes the more fluently the greater the effort she makes to inhibit it. In the midst of a suitable sentence I hold her hand and restrain the writing, and ask her to complete the sentence by word of mouth, which of course she could do if it was her own intelligence, 
that is No. I, that was doing the writing; but she cannot complete the idea, showing that she does not really know what the hand was about to write.

Again, Mrs. B. in hypnosis is told to write automatically when awake, "three times six are eighteen; four times five are twenty." After being awakened she is given something to read aloud; while reading the hand begins to write as previously directed, but she stops reading saying, that she cannot because the, to her, absurd sums three times six are eighteen, four times five are twenty, keep coming into her head. She cannot understand why she should think of such things.

Now, are we to conclude that the mechanism of automatic writing in the second class of writers differs from that performed by the first class, and that when the writer is aware of the automatic thoughts the writing is done by psychical processes, and that when he is not aware of any automatic thoughts it is done by physiological processes? In every other respect, in content of writing and in behavior of the automatic personality to the environment, we find the phenomena are the same. It does not seem to me that such an interpretation is justifiable. As I view this question of the subconscious, far too much weight is given to the point of awareness or not awareness of our conscious processes. As a matter of fact we find entirely identical phenomena, that is identical in every respect but one - that of awareness in which sometimes we are aware of these consicious phenomena and sometimes not; but the one essential and fundamental quality in them is automaticity or independence of the personal consciousness. Doubling and independence of the personal consciousness are therefore the test of the subconscious rather than awareness.

In the content of automatic writing we find evidence which it is difficult to reconcile with a physiological interpretation. This was briefly touched upon before. When studied we find that the writing does not consist of words, phrases and paragraphs which might be mere repetitions 
or memories whether physiological or psychical, of previous experiences, but even consist of elaborate original compositions. Sometimes in Mrs. Verrall's writings they consisted of original Latin or Greek compositions." Sometimes, as in those who are inclined to a spiritistic interpretation, of fanciful fairy-tale-like fabrications. Sometimes they exhibit mathematical reasoning shown by the solution of arithmetical problems. Sometimes they consist of ingeniously fabricated explanations in answer to questions. Sometimes they indicate a personal character with varying moods and temperaments. Feeling and emotion whether of anger, hatred or malice, kindness or amiability are often manifested. If such a document were presented as testamentary evidence in the ordinary course of human affairs, it would seem as if the burden of proof would lie with him who would insist upon interpreting it as without psychological meaning and as only the expression of a physiological activity of the nervous system without thought.

Suggestions in hypnosis may result in post-hypnotic phenomena, which are manifestations of an intelligence which may be of a kind which cannot possibly be explained by physiological habits, as it exhibits logical readjustment of ideas of a high order; for instance, complex arithmetical calculations. The subject is only aware of the final result, being entirely ignorant of the process by which it was arrived at. Later this process can be recalled in hypnosis as conscious memories. To assume that such a calculation can be performed by a brain process not accompanied by thought would seem to require the abandonment of the doctrine of the correlation of mind and brain. In some instances, as with automatic writing, the subject becomes, aware of the automatic conscious process though ignorant of its origin. Are we to assume here again that the processes giving rise to the same manifestations, under the same conditions, differ in kind according as whether. a subject is aware of them or not - in the former case being psychical, in the latter physiological?

' Proc. S. P, R., Vol. XX, p't liii, 1906. 
The great variety of phenomena occurring in abnormal conditions are often explained by the patient in hypnosis as the manifestations of ideas (perceptions, hallucinations, memories, emotions, etc.), which are remembered as such, though unknown to the personal consciousness. [This evidence does nbt differ in kind from that derived from automatic writing (3).]

After all, as I conceive the matter, the one great diffculty in the minds of those who are unable to accept the psychological interpretation of subconscious phenomena lies in understanding how we can have states of consciousness of which we are unaware. Consciousness is represented as a functioning unity, and it is difficult to accept the notion that all states of consciousness are not so synthesized as to form part of that great system which we dub self-conscious. Thus, consciousness is confused with self-consciousness. This has come about because the only immediate experience which anyone has of conscious states is with that which belongs to his self, which is only another way of saying with that of which he is aware. All conscious states, so far as we experience them, belong to, take part in, or help make up a self, - in fact, the expression, "We experience" implies a self that experiences. It is difficult, therefore, to conceive of a conscious state that is not a part of a self-conscious self. It seems queer then, to think of a state of consciousness, a sensation, a perception, an idea floating off - so to speak - by its lonesome self and not attached to anything that can be called a self. It is difficult to conceive of anything worthy of being called a sensation or perception, excepting so far as there is a self to experience it; and yet it really is a näive conception to imagine that we are self-conscious of each and every conscious state that is aroused in correlation with our nervous system. Such a conception is very much akin to the näive notion of scientific materialism which assumes, for the practical purposes 
of experimentation or other reasons, that phenomenal matter really exists as such. Consciousness whether in an elementary or complex form must be correlated with an innumerable number of different physiological brain syntheses. If this is not so the whole structure of the psycho-physiology of the mind and brain falls. We have every reason to assume that some sort of a psychical state occurs when any one of these association-groups is excited to activity. (At any given moment the great mass of them is inhibited.) There is strong reason to believe that though ordinarily there is a harmony in the functioning of these association-groups, yet at times there is considerable disharmony and there is clinical evidence for believing that there may be some independence of activity, especially under pathological conditions (hallucinations, obsessions, etc.), of different brain syntheses.

Without being obliged to determine what brain synthesis belongs to the personal consciousness at any given moment, we are entitled to ask why must we necessarily be aware of all the conscious states which may belong to each and every brain association-group? Is this not a näive assumption? If it is true that dissociated brain systems can functionate (as in other parts of the nervous system), and if it is true that they have psychical equivalents, then whether we are selfconscious of any given state of consciousness must depend, it would seem, upon whether the brain process, correlated with it, is synthesized in a particular way with the larger system of brain processes which is correlated at a given moment with the self-conscious personality. And in so so far as a brain process can occur detached from the main system of brain processes, so far can consciousness occur without self-consciousness. Unfortunately, we have scarcely a glimmer of knowledge of the nature of the synthesis, and therefore of the conditions which determine whether we shall be aware of any conscious state or not. This is a problem in psychology which awaits the future. Nor is selfconsciousness a necessary element of consciousness. The näive character of the notion that we must be self-conscious of our consciousness is shown by introspective analysis in intense mental concentration or absent-mindedness. Here 
is no awareness of self, only a succession of ideas which adjust and readjust themselves. It is not until afterwards, on "returning to one's self," that these ideas through memory become a part of our self-conscious personality.

It will be noticed that an essential element in the conception of the subconscious, as generally held by students of abnormal phenomena, is the absence of awareness of the personal consciousness for the dissociated ideas. A consideration of the facts in their entirety do not permit of so limited a view to which I am compelled to dissent. Theoretically, a conception so narrow prevents our obtaining a broad view of allied psychological phenomena, obscures our perception of the broad principles underlying them and hinders a correlation of closely related conditions. Dissociation, with activity, independent of the main focus of consciousness, does not necessarily imply or require absence of awareness on the part of the latter, and practically, as we have seen in discussing the phenomena of automatic writing, under the same conditions, a subject is sometimes aware of the dissociated ideas which are actively manifesting themselves and sometimes not. The same is true of post-hypnotic and abnormal phenomena. Indeed, even when there is absence of awareness on the part of the personal consciousness, the dissociated co-consciousness may, per contra, be aware of the content of the former. For this reason, if for no other, co-consciousness is the preferable term. The one fundamental principle and criterion of the subconscious is dissociation and co-activity (automatism). When we get rid of this notion of awareness as an essential element, we are able to grasp the relation between the subconsciousness of hysterics and the disaggregation of personality of the psychasthenic, a study with which Dr. Janet says he is now occupied. The obsessions, the impulsions, the fears, in short, the imperative ideas of the psychasthenic are as much disaggregated from the personal consciousness as the same are in the hysteric, excepting for that amount of synthesis that gives awareness. Indeed, the hysteric may have a certain amount of awareness, or awareness for some and not for other ideas. The only difference then between an ordinary obsession and a "subconscious" 
obsession as commonly viewed, is that the subject is aware of the one and not of the other. Undoubtedly the condition of awareness alters considerably the resulting psychical content, as it brings into play various co-operative and modifying and in some measure adjusting ideas. This is not the place to enter into a consideration of the differences and likenesses between psychasthenia and hysteria, but I believe it important to insist that lack of awareness is not an essential fact or in the development of the subconscious, and furthermore that an appreciation of this fact will enable us to better correlate the different varieties of co-conscious activities not only in various diseased conditions but with facts of normal mental life.

Those who maintain the physiological interpretation seem to me to involve themselves in difficulties far greater than any offered by the psychological interpretation. It is a fundamental interpretation of psycho-physiology that all thought is correlated with physiological activities. Whatever doctrine we adopt, whether that of parallelism or psycho-physical identification, every psychical process is correlated with a physiological process and vice versa. We cannot conceive of a psychical activity without a corresponding physiological one. How then can we conceive of a physiological process of a complexity and character capable of exhibiting itself as a spontaneous volitional intelligence without corresponding correlated ideas? Surely this needs explanation quite as much as does a lack of awareness of conscious processes. Yet with a certain modification of our conception of the meaning of the physical, it is possible to reconcile both interpretations. As a panpsychist I find no difficulty in accepting both a physiological and a psychical interpretation. For those who accept panpsychism there is no distinction to be made between conscious processes and brain processes of a certain order, excepting as a point of view. They become identified one with the other. The psychical is the reality of the physical. I cannot conceive of brain processes except as objective phenomena of conscious processes, and I cannot conceive of consciousness excepting 
as the reality or "inner life" of brain changes. So that we may indifferently describe automatic actions as manifestations of physiological activities, if we keep to one set of terms, or of psychical activities if we mix the terms. But in doing this let us not straddle and deceive ourselves as to our real position. In thinking in physiological terms we must not confuse ourselves and, by adopting a terminology, imagne that those physical brain factors are without psychical equivalents. To hold to a pure physiological explanation without the notion of anything psychical as a part of their real nature, is to postulate consciousness as a pure epiphenomenon, something that we can shift in and out at our pleasure, when we have brain action, and juggle with as a conjurer juggles with his coins,- now you see them and now you don't.

It may be that the final explanation of many conscious processes, if we would a void the entanglements of metaphysics, must be in physiological terms, because it must deal with that which belongs to experience. We can experience physiological "after effects," and by a simple inference go back to the physiological functioning forerunner, and thus perhaps explain memory, but, as Professor Münsterberg so well points out, it is difficult to see how a comprehensible explanation of memory can be found in "mental dispositions," and on grounds, as I would state them, that such dispositions being out of consciousness we have no experience of them and can have no conception of what they are. They become nothing more than metaphysical concepts. For myself I cannot even think of a "mental disposition," meaning, for instance, a name or mental picture that is not at the moment a state of consciousness, whether subconscious or belonging to my self-conscious synthesis. However this may be, I not only say with Professor Münsterberg that "the physiological cerebration is well able to produce the 'intellectual' result," but it must be able to do so. The only question is whether it is accompanied by, belongs to, or is another aspect of ideas. This can, to my way of thinking, only be settled by logical inferences from the observed phenomena, and I have endeavored in what has gone before to marshal the evidence so far as it exists today in substantiation of this interpretation. 


\section{ABSTRACTS}

THE energies of MEN. (Delivered as the Presidential Address before the American Philosophical Association at Columbia University, December 28, 1906.) Philosophical Review, 1907.

In this stimulating essay Dr. James has been able to give loose rein to the practical, the human-life, and human-need sympathies that have always so strongly characterized his work, even when he wrote of things abstruse.

Beginning with a reference to the fact that the most important psychology of today is the "medical," the "functional" psychology, the writer goes on to state, as his main thesis, that the store of energy which most persons find available for their daily needs is far below that which - if they did but know it belongs to them by right. It is not only that our intellects are tied down by "literality and decorum," or narrowed by the special claims of our professions and beliefs, but also, and more, that we are unable to command at will the "excitements, ideas, and efforts" that are needed to carry us over the dam within which our energies are confined.

After reciting some remarkable instances of the breaking down of the barriers, through emotions, ideas, and efforts of the will, and after dwelling especially on the striking case of a literary invalid who regained his health and vigor and vivified his mental tone through the severe discipline of the Hatha Yoga, Dr. James goes on to analyze a little further the issues that are here at stake.

Three problems, he thinks, press most of all for a solution, the first being, In what terms can we best define the nature of these gains in mental force ?; the second, What, in each direction, are their limits?; the third, What are the "keys," the "paths of access" to these reservoirs of power?

These are problems to be worked out, not through la boratoryresearch, but through the study of the mental lives of individual men in action, a kind of study in which Papini of Florence has, he says, already been a pioneer. "We ought somehow," the author says, "to get a topographic survey made of the limits of human power in every conceivable direction, something like an ophthalmologist's chart of the limits of the human field of vision; and we ought then to construct a methodical inventory of the 
paths of access, or keys, differing with the diverse types of individual, to the different kinds of power. This would be an absolutely concrete study, to be carried on by using historical and biographical material mainly," and so on.

With this program the writer leaves us, feeling, perhaps, somewhat as Virgil and Dante must have felt when they found themselves, in the grey of that early morning, at the foot of the Mount of Purgatory. Verily, we may be grateful for the program and for the vision of the hilltop, but we shall have a plenty of gratitude remaining for anyone who will point out, in more detail, the ways and means of further progress.

On this question of practical "means" Dr. James does not assume to speak at length, although a variety of suggestions come out incidentally, in the discussion of the cases cited, and of the social and religious movements which have furnished in individual instances the keys for unlocking these stores of latent energy.

These latter influences are classified under the heading of "ideas," though the category of "emotional excitements" would seem equally appropriate for many of them, as also for some of those that are ranged under efforts of the "will." In truth, this is but another illustration of the fact that neither "feeling," "intellect," nor "will" can exist, except in theory, without an intermixture of the other two.

Dr. James points out afresh that the scientific doctor should not be so hide-bound by prejudice as to blind himself to the interest of the great popular, emotional or religious movements that are characteristic of our people and our day. It is not enough to say that they are closely similar to all the superstitions that have come and gone since time began. Each one has its own features, and in general it may be said that each is an improvement on its predecessor.

If the lines of research sketched out in the essay are in reality the best to follow, the task is one in which the medical psychologist can, perhaps, play a more important part than his academic colleague. Two points suggest themselves in this connection.

I. Dr. James says that the contracted field of mental life of the ordinary man may be compared to the contracted field of consciousness of the hysteria patient, but adds that what 


\section{Abstracts}

with the latter is the result of disease is with the former the outcome of an "inveterate habit" which he should learn to overcome. Is this distinction altogether valid, and may we not learn something to our advantage through the admission that the difference between the hysterical patient and ourselves is in detail and degree and not in kind?

2. In the able, if extravagant analysis of "Cosmic Consciousness" by Dr. R. M. Bucke, the argument is made that just as 'self-consciousness," with its power of reasoning in terms of symbols and of concepts, is an outgrowth of "simple consciousness," so we may look forward (on the basis of some slight observation) to the eventual appearance of still higher forms of conscious life.

It is no harder for the cultivated man to express his complex thoughts in fluent speech then for the Bushman to make known his crude ideas in a few and scantily differentiated terms. The barrier which hems in the Bushman is a real one, and yet to some extent a surmountable one, even though one which education and civilization usually pulls down stone by stone. May not a difference of a similar sort separate the person who has learned to dwell in regions of higher orders of energy from his former self? In other words, the barriers that keep us from our best selves are to be overcome not only under a supreme effort of the will, but also (conceivably) through the force of rightly directed education.

The whole address is couched in the glowing language so characteristic of the writer, and would form a fitting commentary to some of Emerson's inspiring sentiments, in prose and verse, on kindred themes. The time is ripe, just now, for exhortations of this sort, and one proof of it lies in the fact the educators of all grades have learned to substitute movement and action for gloomy introspection, and to preach "progress" at all hazards.

May scientific psychology not fail to lend its aid to the great work!

Meantime, it may be borne in mind that light upon these problems may be looked for, not only from psychology but also from physiology, and that, here, laboratory research may be able to assert itself to advantage. The principle of the so-called "physiological reserve" is applicable, perhaps, to the case of 
mental energy as well as to that of the action of the heart, etc., and points to the "prodigality of nature," as discussed by Dr. S. J. Meltzer in his able paper recently published in the Journal of the American Medical Association.

James J. Putwam

1. THE TRAGEDY OF CHICAGO - A STUDY IN HYPNOTISM. By Dr. F. Sanderson Christison, Chicago. Published by the author:

I. UNTRUE confessions. By Hugo Münsterberg. The Times Magaxine, Fanuary, Ig07.

On January 12, 1906, in the city of Chicago, a young married woman was brutally outraged and murdred. Her body was discovered by a young man, one Richard G. Ivins, lying face downward on a manure pile in a barnyard, whither he had gone to attend to his father's horse. Having observed the body he immediately reported the matter to his father at the house, and the father notified the police. The officers who inspected the premises found the woman's hat at her feet, but could discover absolutely no evidence of a struggle. Purse, shopping bag and muff were missing. Around her neck was a hard-drawn copper wire, the ends of which were twisted together. Suspected by the police, Ivins was arrested and charged with the crime, whereupon he is alleged almost immediately to have confessed his guilt. He was subsequently tried by jury, convicted, and despite his protestations of innocence, hanged on June 22, 1906.

Thus was consummated a double tragedy, the first part of which is veiled in mystery, while the second had the sanction and was carried out under the solemn auspices of the law. That Richard Ivins was guilty of a most foul murder, that his "confessions" are true, and his punishment just, - such is the opinion of jury, court and populace in Chicago. That he was innocent of crime, that his "confessions" are the product of a temporarily disordered mind, and his punishment legalized murder,- such is the opinion of Dr. Christison, Professor Münsterberg and other savants, whose views have the weight of authority.

The pamphlet of Dr. Christison contains an impartial, able and thoroughly convincing account of the evidence'upon which'he bases 
his conclusion of Ivin's innocence; while the paper by Professor Munsterberg presents in brief, the psychological principles underlying untrue confessions in general, together with an application of these principles to the particuar confessions under discussion.

As the "confessions" of I vins were the ground upon which he was convicted, and as these confessions wete held to disprove an otherwise complete alibi, Dr. Christison attempts to demonstrate that they were obtained by the police and others, while Ivins was in a condition of hypnosis. The first confession was obtained from the boy by the Assistant Chief of Police, about 10.30 o'clock of the morning on which the body was found. Ivins did not write this confession; he merely signed it. By its composition and the psychological breaks it contains, the fact is placed beyond doubt that it is the product of a series of suggestions or leading questions put to him. The testimony of the police also shows that it is the product of bald assertions, while it is probable that every word in it was suggested to him or simply imputed to him, for the language is known to be, in large part, foreign to his character.

Discussing the conditions under which a confession of this kind might be obtained, Dr. Christison observes that there are three ways of grafting. false ideas upon the minds of those who are rendered passive. The first way is to make a simple statement or series of statements in an apparently sincere and credible manner, under quiet, restful and practically solemn circumstances. In the second method, some statements are made and certain conditions are associated which by inference cause the belief desired, through the natural laws of association of ideas, although the belief may be contrary to reason and experience. The third method consists in employing forceful or awe-inspiring assertions, especially under isolated and uninterrupting circumstances. Memory is disconnected and the reasoning faculty of the susceptible individual is unable to dismiss the ideas suggested or asserted. This third method was precisely what was applied to young Ivins, and not until he was removed from police influence, and the true events were brought to his attention, was he delivered from the grafted delusion.

The second confession which was not written, but was signed by Ivins, is considerably longer than the first. In it are to be observed more markedly just those peculiar features that one would expect to find in an hypnotized subject, - namely, contradictions, freaks of memory and absurdities. A third confession was obtained from the prisoner, in which appear all the characteristics of the other two, with of course, certain unessential variations in detail. 
During the trial, and with these damaging confessions confronting him, Ivins was placed upon the witness stand. He appeared to be calm and gave no evidence of mental perturbation. For everything he did prior to his first alleged confession his memory appeared to be good, and he was in no way shaken in any material statement. But relative to what he is alleged to have confessed to the police and to orhers, he had no recollection whatever, or no distinct recollection, while he did remember some visual and auditory impressions, such as seeing a pistol aimed at him during the coroner's inquest, being shown a "hunk of wire," etc. To the end of his life he maintained his innocence, and among his last words were these: "I suppose I must have made those statements, since they all say I did. But I have no knowledge of having made them, and I am innocent of that crime."

The point upon which Professor Münsterberg desires most particularly to insist is the immense importance of borderland mental cases for the psychology of the court-room. The so-called " confessions" of Ivins serve as the point of departure from which he proceeds to discuss the psychology of untrue confessions in general. The more the scientific analysis and explanation of mental life make progress through the experimental and psychological, comparative and clinical methods, the more we learn how subtle the internal connections are, and how insufficient the popular psychology must be with which the facts of life are usually interpreted by detectives and attorneys, by juries and judges.

Of course in a criminal procedure there can be no better evidence than a confession, provided that it is reliable and well proved; and yet at all times and in all nations experience has suggested a certain distrust of confessions. The danger of accepting them seems to have been felt more strongly at some times than at others; but the essential argument against the trustworthiness of confessions had a purely social origin; it referred to possible promises or to threats by other members of the community.

There is perhaps another motive which might induce a man in full possession of his faculties to declare himself guilty against his better knowledge. It is possible that persons wrongly suspected of a crime may, in the face of an unfortunate combination of damaging evidence, prefer to make a false confession in the hope of a recommendation to mercy. Here belong the confessions in the famous Boone case in Vermont; and in this group we may place not a few of the historic confessions in the Salem witch-craft tragedy.

In those dark chapters of New England history there is also to be found an abundance of other forms of confession which lead us 
step by step from well-balanced calculation to complete alienation through all the borderland regions of mental confusion and disintegration. The untrue confessions from hope or fear, through promises or threats, from cunning calculations and passive yielding, shade off there in Salem into others which are given with real conviction under the pressure of emotional excitement or under the spell of overpowering influence.

Although there is little danger of the false confessions of melancholia or other depressed states being taken for true, does this give sécurity for a proper rating of those illusory confessions which, like the absurdities of the Salem witches, result from the temporary abnormal states of a not-diseased brain? The crude standards of easy-going psychology will not avail here, for we must never forget that there is nowhere a sharp line to be drawn between the symptoms of real mental disease and the variations in normal personalities. There is no mental trait that belongs to mental diseases only; whatever we find is made up of the same material that enters into the normal interplay of human minds. It is the order and harmony which are disturbed, and a trait becomes psychologically alarming as soon as the balance is sufficiently destroyed to make the purposes of life impossible.

There is a transitional region for all mental activities, and nowhere perhaps, is this shown more clearly than in the field of memory, whose characters, even within normal limits, are so various. That we forget is in itself no defect. On the contrary we could not fulfil the purposes of life if we did not disburden our memory constantly of superfluous matter; but it is evident that this suppressing and supplementing of memory ideas makes us unfit for life when it assumes large proportions.

Our knowledge of our own personality and its doing is only a function of memory. We know of ourselves, in a psychological sense, through the connected memory of our actions and of our experiences. As soon as the memory for our own past is lost completely, the pathological character is, of course, evident; and if the ideas which form ourselves become dissociated and groups become split off as a second or a third personality, no one doubts the abnormality of the phenomena. Yet here again we can reach the most hopeless forms through small steps from the experiences of our daily life. Hence the borderland region between the normal variations of personality and the complete pathological destruction of the self demands the most earnest consideration in the court-room.

The so-called "confessions" of Ivins seem to Professor Münsterberg, absurd and contradictory and exactly like the involuntary elaboration of a suggestion put into his mind. His whole 
life history and the expression of his face were in fullest accord with the suspicion that his mind was in a state of dissociation when he began his confessions. Yet there was something obscure in the case. It was difficult to understand how the sudden change from denial to confession was brought about unless there was a sudden external shock or some overwhelming fascination which might be, and has been known in specific instances cited by Professor Münsterterg to cause a disintegration of personality. The clue was furnished a few days before Ivin's death, by a newspaper report, which read in part as follows: "He asserts that his only recollection of the coroner's inquest is that of seeing a revolver pointed at him. He said: I saw the flash of steel in front of me. Then two men got before me. I can remember no more than that about it. Someone told me afterward who the man was; but I had not seen him at all, and I don't recall seeing any other men even until after $I$ had seen the revolver. From the time I was arrested I do not believe that I was myself for a moment, until after I was over here in the jail. Everything about that time was a blur, a blank to me."

"I saw the flash of steel in front of me." And from that moment everything decame a blur and a blank. It was the one missing link in the chain of evidence of his innocence. To the psychologist this evidence was convincing; to the court and to the jury, it held no appeal, and Ivins was hanged on the ground of these logically and psychologically impossible confessions.

\section{J. E. Donley}

analysis of Localization. Illustrated by a Brown-Sequard Case. By C. Spearman. The British Fournal of Psychology. Vol. I, pp. 286-314, 1905 .

The case here reported was that of a miner suffering from compression of the spinal cord at the sixth dorsal vertebra. This caused great loss of movement in the left leg, and an almost complete loss of sensation about the waist and on the right leg. The man had been stabbed in the back twenty-six years before, but did not know that the point of the knife remained imbedded in the spine. After operation the symptoms grew worse at first, then a steady but very slow improvement was noticed. The patient was operated on in October, 1903, and the observations of the present article were made from May to August following.

Both legs were tested on the thighs, the calves, the feet and the toes for (I) perception of passive movement, (2) contact sensi- 
bility, and (3) power of localization. The power of localization was tested in four different ways, as follows: (a) "Simple" localization. The patient's eyes were closed and the limb moved about so that the visual image of position was lost. The skin, shielded by cardboard one centimeter distant, was then stimulated with a bent wire, and the patient indicated with a pen on the card the spot just above the point stimutaled. (b) Localization by "looking;" Volkmann's method. A stimulus was given, the patient then opened his eyes and pointed at the spot without touching it. (c) Localization by "groping"; Weber's method. With closed eyes the patient endeavored to touch the spot stimu.lated by groping for it with his finger. (d) The usual "compass" method, with points both simultaneous and successive.

The threshold for the perception of passive movement was about normal for all the joints of the right (tactually anesthetic) leg and for the left hip, but for the left (parlyzed) knee it was over twenty times the normal, and no amount of movement of the left ankle produced a change in consciousness. Contact sensibility was tested by von Frey's "hair method." Both legs showed a threshold at all points much higher than the normal, but that for the right was uniformly higher than that for the left, varying from $60 \mathrm{gm}$.: $24 \mathrm{gm}$. for the thighs to I $\mathrm{gm}$. $6 \mathrm{gm}$. for the toes. In "simple" localization the median variable error was approximately normal for all points on the right leg and on the left thigh, but three to four times the normal on the left calf, foot and toes. On the other hand, in localization by "looking" and by "groping" the median variable error was from two to four times the normal on all points of both legs. On the thighs and calves the right leg was higher than the left, on the feet the two were about equal, while no the toes the right was slightly lower. The compasses showed the same thresholds for both legs, and the results were approximately normal.

In analyzing localization in the light of these experimental results the author finds three distinct types. In the first type there is an immediate consciousness of the spatial relation of the stimulus, "a pure 'thereness' with reference to the body, and especially, head." This "thereness," or sense of position, would seem to depend on articular excitations, and it is owing to the lack of these articular excitations from the lower joints of the left (paralyzed) leg, as indicated by passive movement, that "simple" localization 
is so vague on that leg below the knee. The second type of localization is that by the mediation of associated spatial images, as illustrated in the "looking" and "groping" procedures. As soon as a point is touched, a mental image is formed of the member and the part stimulated, and the further step is to reproduce this image with the help of vision or touch. Here it is not so much "thereness" as contact sensibility that governs the localization, and on this account both legs show a much higher error than the normal, while the left, being slightly more sensitive, has the lower error of the two. But how is it that this does not extend to the feet and toes? The author thinks that while contact sensibility is the chief factor in the formation of the spatial mental image, there must be an initial localization by a feeling of "thereness." When the articular excitations for this "thereness" are lacking, as in the left foot and toes, the image is vaguer and the error in localization is greater. It is to injury of the tracts conducting the articular excitations that Allocheiria, or transferred localization, is due. The third type of localization, exemplified in the compass tests, is characterized by direct comparison of sensations. Into this the articular excitations do not enter at all, and in spite of the reduction of contact sensibility the threshold of "twoness" remains practically intact.

From the relative amount of disturbance in these three types of localization in the present case the author argues against the position of Forster, "that the movement sensations from the joints are primitive, and the spatial sense of the skin is merely a derivative therefrom." Rather does it seem that all these types have "developed side by side, but the skin has been less hasty to part with earlier modes of function."

$$
\text { J. C. BELL }
$$

\section{REVIEW}

A TEXT-BOOK OF PSYCHIATRY FOR PHYSICIANS AND STUDENTSBy Leonardo Bianchi, M.D.,Professor of Clinical Psychiatry and Neuropathology in the Royal University of $N$ aples. Authorized translation from the Italian by fames $H$. MacDonald, M.B., Ch. B. Glasg.; New York, William Wood E Company, 1906.

Judging from the numerous reviews of and references to Professor Bianchi's work, the English translation has already 
been widely read and consulted as, indeed, it should be since it is probably the most complete text-book on Psychiatry in the English language.

In it the psychiatrist will find much food for thought in the way in which the author has departed from the set nosographical lines so common to text-book descriptions of mental disturbances and has sought to present a broad survey of the whole known world of psychiatric knowledge. Most of our text-books irritate the reader by a persistent and stilted adherence to arbitrary division and boundary lines by means of which the whole subject is cut up into so many blocks like the surface of a frozen pond prepared for the winter ice harvest; the reader like the skater must then bump along, tripping where he might have glided smoothly but for the artificial crevices. With each new text-book one must twist and bend one's mental machinery to fit the casing of each particular author's mind. The labor of reading is further increased by the necessity of reciprocally interpreting the new and the old text-books in terms of each other's nosological captions. In no other branch of medicine is the requirement of learning so impeded by the diverse and arbitrary sundering of a subject possessing such high claims to a natural unity.

It is refreshing, therefore, to the psychiatrist, and should prove of infinite value to the tyro seeking to gain a decent knowledge of psychiatric lore, to follow a book which proceeds naturally from beginning to end along logical lines more or less common to all other medical subjects. By this we do not mean to infer that Professor Bianchi has abandoned all reference by name to individual psychopathic and nosographic forms, for this would leave the reader without sign-posts and symbols upon which as students we have learned to depend while groping our way through murky places. But his tokens do not obscure the landscape and needlessly distract the attention. He has succeeded in doing what few psychiatrists have accomplished in their writings; namely, submerging the temptation to reiterate personal opinion at the expense of straightforward presentation of known facts. He rather harmonizes conflicting opinion in place of making confusion worse confounded. He seeks to simplify matters and facilitate understanding. His purpose is stated in the preface, where he says," ... Where others find nosographic 
differences, I have been led rather to fuse and combine, and sometimes, on the other hand, to draw distinctions between clinical forms that have been confused under one name." Before this declaration and its fulfilment in the text the reader may halt, overcome with the fear that after all the author has been unable to suppress the desire to serve psychiatry a la Bianchi and to offer yet another personally trade-marked and copyrighted rubric to the already superfluous number of ante-mortem monuments raised by ambitious psychiatrists to their own memory. If such suspicion be aroused, let the reviewer put the mind of the reader at rest, for, though it is perhaps too much to demand of human frailty that the psychiatrist shall abstain from recording his guess as to what manner of form this our infant psychiatry is to present in its years of discretion, it is nevertheless true that the Italian author reduces to a minimum this selfish tendency and adheres consistently to the principle of synthesis rather than analysis in presenting his subject.

The book is a large one - though not too large - and if it should be necessary to limit oneself to a one-volume psychiatric library, no better choice could be made thán that of Bianchi's work. The book deals not only with psychopathic forms, but gives a summary of the fundamental laws of the evolution of the mind in relation to the evolution of the nervous system as well as an architectural, anatomical and physiological plan of the human brain. There is a second part, "which is, as it were, an introduction to the clinical section, being devoted to the semeiology of the mental affections, - that is to say, to the examination of the elementary symptoms of the disordered mind, and to the analysis of their signification in relation to the facts of normal psychology and to the laws which govern their manifestation." Pathological anatomy, aetiology and therapy are considered hand-in-hand with the description of each nosographic form in the third and major portion of the book.

Professor Bianchi's expressed hope that the work might meet with the approval of physicians in general and psychiatrists in particular has already been fulfilled, and we join with him in the belief "that even to lawyers and magistrates it will offer a material and means for a surer and clearer vision as regards the new horizon of the law and its altogether modern application."

Wm. McDonald, JR. 